\title{
MEMÓRIA E IDENTIDADE CAMPONESA DAS MULHERES DO NÚCLEO RURAL CAPÃO SECO (DF)
}

\section{MEMORY AND PEASANT IDENTITY OF WOMEN FROM AGRICULTURAL COMMUNITY CAPÃO SECO (DF)}

\author{
Isabella Ferreira Viana Ribeiro \\ Prof $^{a}$. da Secretaria de Educação do Distrito Federal \\ Especialista em História pela Universidade Estadual de Goiás, Campus Formosa-GO, Brasil \\ isabella.fviana93@gmail.com
}

Francilane Eulália de Souza

Prof $^{a}$. Dr ${ }^{\mathrm{a}}$. do Departamento de Geografia da Universidade Estadual de Goiás, Campus Formosa-GO, Brasil francilanee@hotmail.com

\section{Resumo}

O cenário de áreas da região Centro-Oeste vem sendo modificado nas últimas décadas pela introdução de formas de produção agrícola ligadas ao capitalismo, como o agronegócio. O Núcleo Rural Capão Seco é uma comunidade localizada no Distrito Federal que se avizinha ao PAD-DF (assentamento ${ }^{1}$ criado em 1977 com o objetivo de levar o agronegócio à região). Isto posto, objetiva-se compreender a importância do cerrado para a construção da identidade de seus moradores. Destarte, foram realizadas entrevistas com mulheres que há décadas residem no Núcleo Rural do Capão Seco, visando registrar a sabedoria que possuem sobre o lugar e como percebem as mudanças introduzidas pelo agronegócio, uma vez que esse sistema vem ocasionando a devastação do cerrado. Não se trata apenas de compreender as alterações no local, mas dar voz às mulheres que há muito tempo vivem nesta região. A memória delas, pautada pela experiência, pode apontar paradoxos entre a modernização pela introdução do agronegócio e a destruição do cerrado, que tem relegado ao passado alguns elementos fundamentais à cultura dos camponeses da região Centro-Oeste.

Palavras-chave: Identidade Camponesa. Mulheres. Memória. Cerrado. Núcleo Rural Capão Seco, DF.

\begin{abstract}
The scenery of middle west regions in Brazil is been altered the last decades by the introduction of agricultural ways align with captalism, also known as agribusiness. The community of Capão Seco is located at the Federal District, near the region called PADDF (farmers settlement born in 1977, which primary goal was to bring agribusiness to the region). That said, it's intended to understand how important is cerrado bioma on the identity construct of its dwellers. Thus, interviews were taken with women that lives for
\end{abstract}


decades at the Capão Seco rural community, aiming the registry of knowledge and wisdom about the region and how they perceive the chances introduced by agribusiness, taking into account that it leads to cerrado bioma devastation. It isn't just about to understand how the region changed, but give voice to those who lived there most of their lifes. Their memory, ruled by experience, may be able to pinpoint the paradoxes between the modern processes introduced by agribusiness and exaustion of cerrado bioma, which has relegated to the past some key elements of rural communities at middle west region.

Keywords: Peasant identity. Women. Memory. Cerrado bioma. Rural nucleus Capão Seco, DF.

\section{Introdução}

A partir da análise do depoimento de mulheres residentes no Núcleo Rural Capão Seco, o presente trabalho pretende demonstrar que elementos relacionados ao cerrado são determinantes na formação da identidade camponesa de seus moradores, constituindo hábitos e valores que, mesmo após a introdução da agricultura capitalista na região, continuam a ser valorizados e, em certa medida, praticados. O Núcleo Rural Capão Seco, região que foi objeto da pesquisa, é uma comunidade localizada a cerca de $6 \mathrm{~km}$ do PADDF (Programa de Assentamento Dirigido do Distrito Federal), na zona rural do Distrito Federal, cujos primeiros moradores se mudaram para lá há algumas décadas, muitos em decorrência da desapropriação de terras promovida pelo Estado logo após a construção de Brasília.

Seguindo as premissas da história oral, foram realizadas entrevistas com cinco mulheres que residem há mais de 25 anos no N. R. Capão Seco, com idades entre 57 e 87 anos, a fim de descobrir aspectos da história do lugar, referentes, por exemplo, à desapropriação de terras no Distrito Federal e, sobretudo, aos impactos causados pela introdução da agricultura capitalista na região. Além de ajudar a compreender aspectos culturais de sua sociedade, a memória dessas mulheres aponta para as particularidades de cada uma delas bem como para a contribuição delas na formação de uma identidade camponesa pautada pelo contato com o cerrado. Por residirem há mais de duas décadas na região, elas estão aptas a relatar as mudanças ocorridas na comunidade, bem como a sabedoria que trazem sobre a cultura local.

Considerando que o meio camponês do qual essas mulheres são provenientes demorou para acessar a alfabetização, partimos da premissa do historiador Le Goff (2013), que, ao analisar sociedades consideradas "primitivas" por não terem desenvolvido 
a escrita, demonstra como, num mundo iletrado, a memória é fundamental para a perpetuação da história. É nesse sentido que a história oral figura, aqui, como método primordial de investigação, pois, muito mais do que analisar objetos, interessa-nos prestigiar a história de sujeitos. Porém, a decisão de escutar mulheres que viveram a vida toda no campo contarem a história de sua perspectiva não se deve apenas à necessidade de cumprir uma premissa da história oral, mas ao desejo de garantir que esses sujeitos, que por muito tempo foram silenciados, tenham a possibilidade de compartilhar sua sabedoria acumulada pela experiência. Afinal, essas mulheres vivem num ambiente pautado por transformações, que podem resultar no fim de hábitos e valores que por muitas gerações fizeram parte do cotidiano dos camponeses goianos.

A devastação do cerrado, vegetação predominante no Centro-Oeste que sempre fez parte da vida dos camponeses preexistentes à modernização da agricultura, tem provocado mudanças não só no campo material, mas afetado também aspectos culturais desse grupo. Estudiosos já preveem que os danos causados ao bioma nas últimas décadas sejam irreversíveis: as pesquisas realizadas por Barbosa (2015), por exemplo, indicam que o cerrado vem sofrendo devastações em grande escala nas últimas décadas. Sendo assim, torna-se fundamental o registro da memória dos povos que tiveram ou ainda têm uma relação de proximidade com esse meio. Os relatos apresentados nesta pesquisa podem apontar a contradição que passa a existir no Centro-Oeste brasileiro nas últimas décadas a partir da construção da nova capital, acompanhada pela modificação do cenário natural, o cerrado, que impactou o modo de vida camponês anterior à implantação da nova dinâmica agrícola.

\section{A história oral como metodologia de acesso à memória dos camponeses}

A iniciativa desta pesquisa surgiu a partir da construção do inventário ${ }^{2}$ do Centro Educacional do PAD-DF (escola do campo que atende comunidades vizinhas por ser a única da região a oferecer ensino médio), por professores da instituição, durante o segundo semestre de 2018. Em visita à comunidade próxima, o Núcleo Rural Capão Seco, procuramos a moradora Tercina Neres de Santana, por ser conhecedora de plantas medicinais extraídas do cerrado. Sua sabedoria havia sido mencionada pela neta, que cursa o ensino médio no Centro Educacional do PAD-DF. Por intermédio de Tercina, 
conhecemos Valdeci Alves de Sousa, que mora ali há mais tempo que a primeira. O depoimento das duas apontou uma riqueza de saberes camponeses, sobretudo a respeito do cerrado, ao mesmo tempo em que sinalizou para contradições relacionadas à transformação do cenário da região pela introdução da agricultura capitalista.

As possíveis problematizações suscitadas pelas entrevistas com essas duas mulheres mereciam ser aprofundadas em trabalhos acadêmicos, o que fez com que um novo sentido fosse dado à pesquisa, com o objetivo de analisar o impacto da devastação

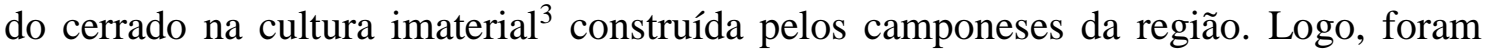
entrevistadas outras mulheres do N. R. Capão Seco para confirmar e enriquecer os depoimentos anteriores. Feitas as devidas apresentações previamente, as entrevistas contidas neste trabalho foram realizadas entre os meses de novembro e dezembro de 2018. As cinco foram entrevistadas em casa, com o intuito de que se sentissem à vontade ao responderem as perguntas, que faziam parte de um roteiro preestabelecido. Cada entrevista durou, em média, 40 minutos, com variações que se deram de acordo com a disposição das entrevistadas.

A metodologia aqui adotada segue as premissas indicadas pela história oral, que tem se mostrado uma importante ferramenta de investigação do passado mais recente, principalmente quando se trata da vida de sujeitos negligenciados pela historiografia tradicional, ligada às fontes escritas. Como já mencionado na introdução, nosso objeto de análise é um grupo camponês que se tornou letrada tardiamente, o que é comprovado pelo fato de a maioria das mulheres entrevistadas serem analfabetas.

\footnotetext{
Inerente às entrevistas, existe, entretanto, uma dimensão simbólica, que os historiadores têm a obrigação de conhecer e estudar, pois faz parte da história. Mediadas pela memória, muitas entrevistas transmitem e reelaboram vivências individuais e coletivas dos informantes com práticas sociais de outras épocas e grupos. A dimensão simbólica das entrevistas não lança luz diretamente sobre os fatos, mas permite aos historiadores rastrear as trajetórias inconscientes das lembranças e associações de lembranças; permite, portanto, compreender os diversos significados que indivíduos e grupos sociais conferem às experiências que têm. Negligenciar essa dimensão é revelar-se ingênuo ou positivista (AMADO, 1995, p. 11).
}

A história oral tornou-se fundamental para esta pesquisa na medida em que se mostrou muito eficaz para alcançar a dimensão cultural do mundo em que vivem essas mulheres. Nesse sentido, ainda que dispuséssemos de um conjunto de documentos a respeito da história do N. R. Capão Seco, estes não conseguiriam abarcar toda a complexidade das relações existentes entre os sujeitos dessa comunidade. 


\begin{abstract}
A fonte oral pode não ser um dado preciso, mas possui dados que, às vezes, um documento escrito não possui. Ela se impõe como primordial para compreensão e estudo do tempo presente, pois só através dela podemos conhecer os sonhos, anseios, crenças e lembranças do passado de pessoas anônimas, simples, sem nenhum status político ou econômico, mas que viveram os acontecimentos de sua época (MATOS; SENNA, 2011, p. 7).
\end{abstract}

Veremos adiante que a fala das mulheres entrevistadas revela essa dimensão simbólica que nos é apresentada pelo resgate da memória. Não obstante, para que se atinja o teor qualitativo das fontes orais, é preciso submeter as evidências a uma análise estrutural, considerando que elas utilizam a memória como forma de acesso ao conhecimento, e que esta ferramenta é caracterizada por uma série de fragilidades. As críticas, nesse sentido, são direcionadas “à confiabilidade da fonte, pois muitos dizem que os depoimentos orais são fontes subjetivas, relativas à memória individual, às vezes falível ou fantasiosa" (MATOS; SENNA 2011, p. 8). Mas não há fonte que se furte à subjetividade. Embora a historiografia tradicional acreditasse ser possível alcançar a objetividade, a Nova História, ao contestar essa premissa, aponta as fragilidades da construção historiográfica, admitindo que o passado não pode ser apreendido de forma total. Até mesmo a utilização de documentos escritos não é completamente eficiente nesse sentido, o que coloca a memória, criticada por ser um instrumento carregado de subjetividade, no mesmo patamar das outras fontes. Segundo Paul Thompson (1992, p. 137 apud MATOS; SENNA, 2011, p. 8), "nenhuma fonte está livre da subjetividade, seja ela escrita, oral ou visual. Todas podem ser insuficientes, ambíguas ou até mesmo passíveis de manipulação”. Tanto as fontes escritas quanto as orais são subjetivas, pois são fruto de uma construção narrativa. Isso posto, podemos admitir que se faça uso de uma diversidade de fontes para se chegar a uma compreensão razoável do passado.

Recorrer à história oral como método de estudo de eventos passados é uma atitude recente no Ocidente, considerando que a tradição historiográfica europeia, por muito tempo pautada pelo positivismo, desautorizava esse tipo de fonte, dando prioridade ao que chamamos de documentos oficiais, como testamentos, certidões e etc., justamente por estarem vinculados à história escrita. Além disso, essa historiografia positivista, que pretendia ser política, privilegiava os grandes eventos e os grandes personagens, deixando de lado uma gama de perspectivas que também poderiam ser caras à história, como as daqueles marginalizados pelas sociedades, que compreendiam, por sinal, a massa de suas populações: mulheres, idosos, camponeses. “A história tradicional oferece uma visão de 
cima, no sentido de que tem sempre se concentrado nos grandes feitos dos grandes homens, estadistas, generais ou ocasionalmente eclesiásticos" (BURKE, 2011, p. 12).

A história positivista, por buscar uma objetividade que hoje sabemos ser inatingível, desconsiderou fontes como a memória justamente por julgá-las pessoais demais. Não obstante o fato de a memória ser oriunda de lembranças particulares, ela está inserida em um contexto social que não pode ser desconsiderado pelos estudiosos. Hoje, destacam-se correntes historiográficas - muito influenciadas por ciências mais recentes como a sociologia, a psicologia e a antropologia - que se valem da memória como uma valiosa ferramenta de reconstrução do passado. Burke, ao narrar a trajetória da Nova História, aponta um rompimento desta com diversos parâmetros da história tradicional, principalmente com relação ao uso das fontes. O novo historiador, longe de acreditar que só os grandes têm história, pensa que "tudo tem uma história" (BURKE, 2011, p. 11). Ampliam-se os objetos de estudo; há um redirecionamento de foco dos acontecimentos às estruturas que levaram a eles; depreende-se que a historiografia, mais do que nunca, precisa dar voz aos marginalizados; valoriza-se novas fontes, para além dos documentos escritos; e, por último, contesta-se a pretensa objetividade dos positivistas.

É importante ressaltar, no entanto, que a história oral só é capaz de abranger um passado mais recente, já que se vale da memória como fonte. Uma pessoa com 50 anos de idade não pode, é claro, afirmar ter presenciado eventos que aconteceram cem anos atrás. Quando muito, o indivíduo se vale do que Pollak (1992) chama de "memória herdada", que trata da introjeção de fatos ocorridos pelos antepassados de uma sociedade e que, por isso, fazem parte de seu imaginário coletivo.

Quais são, portanto, os elementos constitutivos da memória, individual ou coletiva? Em primeiro lugar, são os acontecimentos vividos pessoalmente. Em segundo lugar, são os acontecimentos que eu chamaria de "vividos por tabela", ou seja, acontecimentos vividos pelo grupo ou pela coletividade à qual a pessoa se sente pertencer. São acontecimentos dos quais a pessoa nem sempre participou, mas que, no imaginário, tomaram tamanho relevo que, no fim das contas, é quase impossível que ela consiga saber se participou ou não. Se formos mais longe, a esses acontecimentos vividos por tabela vêm se juntar todos os eventos que não se situam dentro do espaço-tempo de uma pessoa ou de um grupo. É perfeitamente possível que, por meio da socialização política, ou da socialização histórica, ocorra um fenômeno de projeção ou de identificação com determinado passado, tão forte que podemos falar numa memória quase que herdada (POLLAK, 1992, p. 2).

A capacidade da memória de introjetar na vivência do indivíduo elementos que ele não viveu diretamente mostra que ela é um instrumento forjado muito mais pelas 
relações sociais do que por uma consciência individual de mundo. Trata-se, aqui, de pensar a memória enquanto uma combinação de saberes adquiridos coletivamente. Halbwachs (2003) afirma que nossa maneira de observar o mundo não se constrói por percepções puramente individuais, posto que é influenciada pela convivência com outras pessoas. Mesmo que deixemos de fazer parte de determinado grupo, por exemplo, o reencontro com seus membros faz ressurgir lembranças daquele período. Até mesmo o que podemos chamar de memória individual, assim, é fruto da relação que temos com nosso meio social.

Analisando essa noção de memória coletiva, Ricoeur (2007, p. 130) afirma ser “a partir de uma análise sutil da experiência individual de pertencer a um grupo, e na base do ensino recebido dos outros, que a memória individual toma posse de si mesma”. Essa perspectiva dialoga com a visão de Halbwachs (2003), uma vez que o que podemos chamar de particular na memória é a intensidade com que cada pessoa a vivencia, de acordo com a importância que confere ao fato lembrado.

\begin{abstract}
Contudo, se a memória coletiva tira sua força e sua duração por ter como base um conjunto de pessoas, são os indivíduos que se lembram, enquanto integrantes do grupo. Dessa massa de lembranças comuns, umas apoiadas nas outras, não são as mesmas que aparecerão com maior intensidade a cada um deles. De bom grado, diríamos que cada memória individual é um ponto de vista sobre a memória coletiva, que esse ponto de vista muda segundo o lugar que ali ocupo e que esse mesmo lugar muda segundo as relações que mantenho com outros ambientes (HALBWACHS, 2003, p. 69).
\end{abstract}

As diversidades de ponto de vista diante da memória coletiva tendem a ser mais numerosas quando se ampliam os grupos de contato dos indivíduos. Nesse sentido, a dificuldade de acesso desses sujeitos a outras formas de organização tende a fazer com que perpetuem seu modo de vida, na medida em que integrantes de sociedades tecnologicamente desenvolvidas estão mais propensos a mudanças e também mais preparados para aceitá-las.

Evocando a noção de identidade, podemos evidenciar características próprias da sociedade camponesa que se contrapõem à dinâmica das sociedades urbanas contemporâneas. Ao analisar o que chama de sujeitos pós-modernos, Hall (2006) afirma que a identidade, antes considerada estável, vem se tornando cada vez mais fragmentada e contraditória. Segundo ele, “o próprio processo de identificação, através do qual nos projetamos em nossas identidades culturais, tornou-se mais provisório, variável e problemático" (HALL, 2006, p. 12). Partindo dessa perspectiva, o camponês, que via na 
terra um meio de subsistência, mostra-se muito mais atrelado à tradição, cujo rompimento não implicou necessariamente no esquecimento de suas raízes. Isso se dá porque a identidade camponesa foi construída a partir da relação dos sujeitos com a terra, associação evocada em vários momentos das entrevistas aqui realizadas, pois as mulheres sempre mencionavam o potencial autossuficiente da antiga economia e, inerente a este, a solidariedade compartilhada pelos envolvidos na organização precedente. Dessa forma, a introdução da agricultura capitalista não apenas retirou dos camponeses a propriedade da terra, economicamente falando, como também feriu a dinâmica social a ela inerente.

\begin{abstract}
A relação do camponês com a terra se assenta nas raízes características da economia camponesa. Assim, a terra é objeto de posse definido tradicionalmente e não necessariamente objeto de posse legal. A agricultura familiar é constituída pela unidade básica de posse camponesa, produção, consumo, e vida social, formando um todo invisível. O ritmo da agricultura define o ritmo da família e esta se identifica com a posse da terra. (SHANIN, 1976 apud DUARTE, 1998, p. 116).
\end{abstract}

Duarte (1998) reconhece que ainda existem problemas de delimitação conceitual para o campesinato. As primeiras tentativas de caracterização do camponês brasileiro sem contar as formas pejorativas que percebiam o sujeito do campo apenas como um ser atrasado - foram construídas a partir de análises de casos europeus, sobretudo dos ingleses. De acordo com o autor, há muito o que se pesquisar sobre a cultura dos camponeses, especialmente em Goiás, onde a expansão capitalista foi iniciada há poucas décadas "e onde convivem a grande, a média e a pequena propriedades, juntamente com empresas agropecuárias tecnificadas, e onde o camponês continua resistindo à completa expropriação" (DUARTE, 1998, p. 116). Essa resistência não diz respeito apenas à posse da terra, mas também trata da manutenção da identidade desses sujeitos.

Antes de adentrarmos o universo camponês das mulheres do N. R. Capão Seco, apresentado a partir da recorrência à memória, é preciso elucidar o processo histórico sobre o qual a formação dessa comunidade está assentada, mostrando o quanto algumas decisões políticas e econômicas foram determinantes para a alteração da dinâmica das sociedades camponesas preexistentes na região. 
Das mudanças ocorridas no Centro-Oeste brasileiro e da criação do N. R. Capão Seco

A colonização do Centro-Oeste brasileiro vem acontecendo desde o estabelecimento da atividade mineradora na região, após a descoberta de ouro pelas bandeiras paulistas. Sabemos, no entanto, que a mineração do ouro entrou rapidamente em decadência, devido a sua exploração intensiva. Assim, restou aos ocupantes da região centro-oeste o investimento na atividade agropecuária, que já era praticada não só pela necessidade de suprir a alimentação dos habitantes, mas pela facilidade proporcionada pelo espaço característico do local e pelo baixo custo da atividade em si.

Já em 1780, essa atividade encontrava-se em decadência e a população local, que não retornou para o litoral, dedicou-se a uma agricultura de subsistência e à formação das grandes fazendas para prática da pecuária extensiva. Economicamente, a pecuária era a atividade mais viável para a região, por exigir, apenas, pastagens naturais, pouca mão-de-obra, instalações rústicas e reduzido investimento de capital. (FERREIRA; MENDES, 2012, p. 4).

No entanto, mesmo que o povoamento dessa região tenha se iniciado no século XVIII, a quantidade de pessoas que ali se estabelecera era ainda muito parca se comparada a outras regiões do país, como a Sudeste e a Nordeste. É somente no século XX, durante o Estado Novo de Vargas, que a população do lugar começou a crescer efetivamente, graças ao incentivo federal que visava povoar as regiões consideradas inóspitas no país, através da chamada "Marcha para o Oeste brasileiro".

[...] foi inaugurada pelo governo federal uma campanha largamente difundida pela imprensa, intitulada Marcha para o Oeste. Esta campanha tinha como principal objetivo o povoamento, a ocupação econômica e a modernização sociocultural das regiões Amazônica e Brasil Central. Foi então, que para subsidiar esta grande empreitada, foi criada em 1943 a Fundação Brasil Central (FBC). (MACIEL, 2005, 146 apud SANTOS, 2016, p. 4).

O Centro-Oeste era, até então, reconhecido pela atividade agropecuária basicamente voltada à subsistência. No entanto, a partir da década de 1960, o cenário do cerrado brasileiro começou a ser modificado pelo investimento em novas técnicas agrícolas, que vinha sendo estimulado por capitalistas de grandes potências, como os Estados Unidos da América e Japão (estávamos, afinal, imersos na bipolarização ocasionada pela Guerra Fria). Aliado a isso, temos ainda a recém-inauguração da nova capital brasileira, Brasília, construída em tempo recorde - "50 anos em 5", como se 
regozijou o então presidente da república, Juscelino Kubitschek, ao estabelecer seu Plano de Metas. Não obstante o mérito que se confere ao líder pela realização de tal feito, a interiorização da nova capital fazia parte de um projeto antigo, anterior à fundação da República. Esse projeto seria mais tarde formalizado pela primeira constituição do Brasil republicano e retomado pela carta de 1946, que regia o país durante o mandato de Kubitschek.

A construção da nova capital correspondia a uma utopia que pretendia afastar o Brasil do passado colonial, atrasado. Para Magalhães (2004), Brasília não seria o final de "uma trajetória marcada pelas mutilações herdadas do colonialismo, mas, seu contrário, o ponto de partida para uma nova era ou o encontro de um povo com seu inevitável destino de grandezas e glórias - o ciclo desenvolvimentista nacional” (MAGALHÃES, 2004, p.18). Porém, o projeto que objetivava conectar as diferentes regiões do país, ao mesmo tempo em que traria a modernização para o interior, não considerou a sobrevivência do modo de vida das populações que já habitavam o que se tornou o território do Distrito Federal. Para que Brasília existisse, era necessário realizar a desapropriação das terras, constituídas pelo bioma cerrado e pelas fazendas agropecuárias que ocasionalmente o rasgavam. Para executar essa tarefa, “criou-se a Companhia Urbanizadora da Nova Capital do Brasil (NOVACAP), responsável pela desapropriação de terras situadas no DF (Lei 2.874/1956)" (BARROSO; FORTES; GUEDES; SILVA, 2007, p. 5235).

Em termos de legislação, dado que não se pode compreender a estrutura de uma sociedade sem se considerar os mecanismos legais que a governam, temos a Brasília recém-inaugurada regida pela Lei 3751 de 13 de abril de 1960 (Lei Orgânica do Distrito Federal), que inicialmente previa o comando do ente por um prefeito e por dois secretários-gerais; nessa lei, prevalecia uma estrutura muito mais desconcentrada, com a existência de órgãos vinculados à administração central. Tais órgãos foram sendo criados com o tempo, pois, conforme o crescimento da população e, com ela, o aparecimento de problemas sociais, tornou-se urgente o aperfeiçoamento da estrutura governamental. Além disso, valendo-se de seu poder de criar instrumentos de administração descentralizada, a liderança do Distrito Federal logo decretou a criação de empresas e fundações, dentre as quais a Fundação Zoobotânica do Distrito Federal (Decreto $\mathrm{n}^{\circ}$ 48.926, de 08 de setembro de 1960), que nos interessa por ser a instituição responsável pela desapropriação de terras na área rural aqui estudada ${ }^{4}$. 
De acordo com Lyrio (1973), a partir de 1964, ano de estabelecimento da ditadura militar no Brasil, a estrutura política do Distrito Federal sofreu alterações com a introdução da chamada Reforma Administrativa, formalizada pela Lei 4.545 de 10 de dezembro de 1964, que propunha reformar também o campo funcional, a fim de que as formas de controle e execução dos serviços se exercessem mediante uma organização sistêmica, no sentido de alcançar a centralização do controle e a descentralização da execução. Nota-se, aí, uma disposição tendente à centralização do controle, elemento característico da ditadura militar, que ampliou os poderes do presidente da república. Aliaram-se à Lei da reforma outras disposições que tratam do uso das terras do Distrito Federal, amparadas pela Lei federal 4.504, também promulgada em 1964, que dispõe sobre o Estatuto da Terra. Fica evidente, logo no primeiro artigo do Estatuto, o interesse em relação às terras.

\footnotetext{
Art. $1^{\circ}$ Esta Lei regula os direitos e obrigações concernentes aos bens imóveis rurais, para os fins de execução da Reforma Agrária e promoção da Política Agrícola.

$\S 1^{\circ}$ Considera-se Reforma Agrária o conjunto de medidas que visem a promover melhor distribuição da terra, mediante modificações no regime de sua posse e uso, a fim de atender aos princípios de justiça social e ao aumento de produtividade.

$\S 2^{\circ}$ Entende-se por Política Agrícola o conjunto de providências de amparo à propriedade da terra, que se destinem a orientar, no interesse da economia rural, as atividades agropecuárias, seja no sentido de garantir-lhes o pleno emprego, seja no de harmonizá-las com o processo de industrialização do país. (SEDUH/DF, 1964, p. 1).
}

Considerando os fatos que envolvem a questão agrária no Brasil, percebemos que apenas uma parte do disposto no trecho reproduzido acima foi cumprida. A distribuição da terra nunca ocorreu de forma igualitária no Brasil, ao contrário, nosso país, desde os tempos coloniais, foi caracterizado pela concentração de terras e pela truculência no trato para com os camponeses. "Muito antes do golpe militar de 1964, o campo brasileiro já era um trágico palco de abusos e assassinatos de trabalhadores rurais. A violência, como se sabe, atravessou todo o processo de colonização do país" (CARNEIRO; CIOCARI, 2010, p. 21). Justamente no período em que se estabelece o Estatuto da Terra, ocorre uma forte repressão, por parte do governo central, às Ligas Camponesas que lutavam pela Reforma Agrária. As ações repressoras eram executadas diretamente por agentes do governo ou por latifundiários amparados pelos primeiros. 
Quase todos os dirigentes das Ligas foram presos ou mortos. No dia 21 de abril de 1964, o Diário de Pernambuco noticiava que a polícia havia encontrado o corpo do presidente das Ligas Camponesas de Vitória de Santo Antão, Albertino José da Silva, em adiantado estado de decomposição. Nessas execuções sumárias, ficavam evidentes os compromissos entre o latifúndio e o poder militar que comandava o país. (CARNEIRO; CIOCARI, 2010, p. 23).

Esse cenário de repressão aos camponeses, aliado a outros fatores, como a valorização das terras próximas à Brasília e as políticas de modernização da agricultura que passaram a ser introduzidas pelo Estado, acarretou uma série de transformações na região Centro-Oeste. O contexto de desapropriações em que Brasília foi fundada continuou ocorrendo nas áreas rurais, devido à necessidade de criar uma base de suprimentos para a população da nova capital. "A ocupação rural do território do Distrito Federal processou-se através da implantação de núcleos rurais e colônias agrícolas, e de programas especiais de assentamento agropecuário" (SILVA, H., 2006, p. 5). Nesse sentido, a necessidade de manter a função social da terra não respeitou a manutenção das culturas de subsistência preexistentes na região.

A veracidade de tais ações pode ser confirmada pela história oficial e pelo depoimento de pessoas que vivenciaram o período. Durante A década de 1960, Brasília “estava ainda em processo de consolidação como centro político e administrativo, e o governo federal tinha grande interesse em desenvolver as regiões vizinhas e em ocupar os cerrados" (BRAGA, 1998, p. 97). É este o caso da formação do N. R. Capão Seco que, segundo as entrevistas que serão analisadas adiante e as políticas de modernização da agricultura na região centro-oeste, tem sua origem atrelada às desapropriações promovidas pelo Estado.

O N. R. Capão Seco situa-se no sudeste do Distrito Federal e avizinha-se do PADDF (Programa de Assentamento Dirigido do Distrito Federal), área de aplicação do agronegócio, iniciado em 1977. Apesar da proximidade entre essas comunidades, nota-se que a finalidade de ambas é muito diversa, o que não impede, é claro, a existência de relações entre elas, afinal foram constituídas no mesmo cenário de desapropriação e modernização das áreas rurais do DF. Temos, então, o N. R. Capão Seco, composto por moradores expropriados de suas terras, e o PAD-DF, formado por agricultores vindos em sua maioria da região sul do Brasil, onde já havia o cultivo da soja, para implantar culturas voltadas ao agronegócio.

No site da COOPA-DF (Cooperativa do PAD-DF), vê-se um slogan que confirma 
sua ligação com o projeto de levar o agronegócio à região: "transformando o cerrado em campos férteis". No endereço eletrônico, encontramos links que contam a história do assentamento, explicitam seus objetivos e divulgam eventos que movimentam ali o agronegócio. Podemos mencionar a AgroBrasília, considerada "uma das maiores feiras de agronegócio do Brasil, que tem se destacado como celeiro de inovações e realização de negócios, junto às melhores empresas do setor e agricultores em busca de tecnologia" (COOPA-DF, 2016). O evento é anunciado como "Feira Internacional dos Cerrados", nome que evoca a transformação do bioma a partir da introdução desse tipo de agricultura.

Diferentemente das formas tradicionais camponesas de cultivo da terra, voltadas para a subsistência, a agricultura capitalista ligada ao agronegócio preocupa-se com a geração de lucro a partir da introdução de novas técnicas de cultivo operadas em latifúndios de monoculturas, sendo amparada por uma rede de apoio composta por bancos, indústrias e também pelo Estado.

\begin{abstract}
Na verdade, o agronegócio é uma versão contemporânea do capitalismo no campo, correspondendo a um modelo no qual a produção é organizada a partir de aparatos técnico-científicos, grandes extensões de terras, pouca mão-obra, predomínio da monocultura, dependência do mercado no quanto e como produzir, enfim, a empresas rurais. Para o Estado, esse é o modelo que fez prosperar e desenvolver o campo brasileiro, porque contribui com o PIB (Produto Interno Bruto), responsável pelo crescimento da economia, empregos e produção de alimentos. (MATOS; PESSÔA, 2011, p. 4).
\end{abstract}

Nesse período, foram lançados vários programas de incentivo ao desenvolvimento econômico do setor agropecuário no Brasil, dentre eles o Polocentro, direcionado à região do cerrado, e o Proceder ${ }^{5}$, que visava estabelecer assentamentos voltados ao agronegócio (BRAGA, 1998). O PAD-DF recebeu os incentivos do último programa.

\footnotetext{
O Programa de Assentamento Dirigido do Distrito Federal - PAD/DF foi elaborado em 1977, segundo as premissas do PROCEDER. A partir desta constatação, podemos afirmar que, dentro do contexto geral, a elaboração e implantação do PAD/DF está inserida na dinâmica de ampliação da acumulação capitalista para as regiões de fronteira. No sentido específico do projeto, enquanto expressão de uma política de conteúdo regionalizado, podemos supô-lo uma frente de expansão da agricultura comercial na região Centro-Oeste, patrocinada pela aliança do capital nacional e internacional, com o aval do Estado. (ROCHA, 1992, p. 75).
}

De acordo com os apontamentos de Matos e Pessôa (2011), o Estado brasileiro considerava o campo um local atrasado e optou pelo tipo de reforma agrária que traria a modernização que já havia sido introduzida em outros países desde a chamada Revolução Verde $^{6}$. Falava-se na implantação da agricultura em larga escala como uma solução para 
os problemas de escassez de alimentos e como fator de melhoria da qualidade de vida das populações do campo. "Todavia, essas orientações tomaram outros rumos: a modernização do latifúndio e a expulsão de milhares de pessoas do campo para a cidade" (MATOS; PESSOA; 2011, p. 6), além da devastação do cerrado, que tem provocado alterações não só de cunho material, mas também cultural, na dinâmica das sociedades que preexistiam nessa região.

\begin{abstract}
Apesar da relativa preocupação do governo federal com a matéria, revelada logo após a Conferência das Nações Unidas sobre Meio Ambiente Humano, ocorrida em Estocolmo, em 1972, a nosso ver, a questão ambiental não se configurou como tema realmente relevante na agenda governamental, no momento da elaboração das políticas desenvolvimentistas. (BRAGA, 1998, p. 104).
\end{abstract}

A expansão acelerada da agricultura capitalista ligada ao agronegócio vem causando uma devastação irreversível no cerrado, afetando, consequentemente, a cadeia ambiental dependente dele. Segundo Medeiros (1998), consequências como o empobrecimento do solo, os desmatamentos e queimadas e as contaminações por agrotóxicos são alguns dos impactos negativos da expansão agropecuária.

\begin{abstract}
A utilização de adubos químicos e de agrotóxicos, a intensa e concentrada mecanização e as extensas monoculturas voltadas para o mercado externo causaram erosão e degradação de terras agrícolas, assim como sérios impactos sobre os recursos florestais, sobre os rios e os lagos, sobre o equilíbrio biológico de pragas e doenças. (MEDEIROS, 1998, p. 132).
\end{abstract}

O cerrado é um bioma de extrema relevância para a manutenção do equilíbrio ambiental brasileiro. Segundo Barbosa (2015), esse bioma demorou mais 60 milhões de anos para evoluir e possui uma estrutura complexa que, se modificada, pode causar danos irreversíveis à cadeia que dele depende.

O Cerrado, diferente dos outros matizes ambientais brasileiros, tem que ser entendido como um sistema biogeográfico. Sistema é um conjunto de elementos intimamente interligados, e qualquer modificação em um desses elementos provoca alterações maiores no sistema como um todo [...] A cobertura vegetal do cerradão, na área plana, é que garante a infiltração da água da chuva nas raízes das plantas. Retirada essa cobertura, a infiltração não ocorre como deveria, e isso prejudicará em maior ou menor grau todos os demais ambientes. (BARBOSA, 2015).

A destruição do cerrado, de acordo com este autor, vem causando o colapso de toda uma cadeia ambiental, não só entre a fauna e a flora interiores, mas também em outros biomas que ele ajuda a sustentar, já que as raízes de suas árvores são responsáveis 
pela captação da água da chuva. Destruídos esses mecanismos, torna-se uma tarefa difícil

- quase impossível - reestruturá-los. Além da questão ambiental, o especialista menciona

o fator social por trás da destruição do cerrado, como o êxodo rural e os saberes que precisam ser preservados.

\begin{abstract}
Inúmeras plantas medicinais incorporadas à farmacopeia internacional têm origem no Cerrado. O quinino, que cura malária... ficaríamos a tarde toda enumerando as contribuições. Todos os tipos de pimenta vêm da Malagueta, que é nossa. Mas, sem dúvida alguma, a maior contribuição é mesmo a sabedoria, o exemplo da relação saudável com a Natureza, que ainda não aprendemos, mas ainda podemos aprender se as escolas cumprirem a função para a qual foram criadas. Só que não há uma eternidade para isso. Se o Homem não mudar seu procedimento, chegará o dia em que será tarde demais. (BARBOSA, 2015).
\end{abstract}

Considerando os fatores apontados até aqui, é possível afirmar que a introdução da agricultura capitalista na região observada tem impactado a organização social ali preexistente. Há momentos em que as entrevistas realizadas com as mulheres do N. R. Capão Seco mostram as controvérsias presentes na relação entre as duas comunidades que, mesmo muito próximas, nasceram e seguem existindo com finalidades diferentes. Por exemplo, quase todas as entrevistadas têm a noção de que o agronegócio, ao mesmo tempo em que devastou o cerrado, melhorou a infraestrutura das comunidades vizinhas, incluindo a sua. Mesmo assim, foi unânime a concordância com a acelerada mudança provocada na paisagem local. Basicamente, quase tudo o que se vê, hoje, ao redor da comunidade, são lavouras de monocultura.

Além dos danos ambientais causados pela modernização da agricultura, interessanos, sobretudo, perceber quais foram os impactos na cultura local. O que se perdeu em termos de riqueza imaterial após a devastação do cerrado? As entrevistas com as mulheres do N. R. Capão Seco podem apresentar respostas a essa indagação.

\title{
A cultura relacionada ao cerrado pela voz de mulheres do N. R. Capão Seco
}

Muitos dos paradigmas apontados pela Nova História se enquadram no estudo aqui realizado, sobretudo os três últimos. Por exemplo, a opção por entrevistar mulheres que vivem no campo demonstra o interesse por dois tipos de sujeitos historicamente marginalizados: as mulheres e os sujeitos do campo. Esse tipo de objeto de estudo enquadra-se na linha de pensamento denominada "história vista de baixo", que se opõe à 
tradicional história política, que apenas se importava com ditos "homens grandes". De acordo com Sharpe (2011), o interesse por se contar a história dos marginalizados vem sendo suscitado há poucas décadas, principalmente pelos escritos de Edward Thompson (1965), que verá nos camponeses ingleses uma rica fonte de compreensão de sua época, justamente por nos mostrarem um mundo que se encontrava praticamente soterrado.

\begin{abstract}
Estou procurando resgatar o pobre descalço, o agricultor ultrapassado, o tecelão do tear manual "obsoleto", o artesão "utopista" e até os seguidores enganados de Joanna Southcott, da enorme condescendência da posteridade. Suas habilidades e tradições podem ter-se tornado moribundas. Sua hostilidade ao novo industrialismo pode ter-se tornado retrógrada. Seus ideais comunitários podem ter-se tornado fantasias. Suas conspirações insurrecionais podem ter-se tornado imprudentes. Mas eles viveram nesses períodos de extrema perturbação social, e nós não. (THOMPSON, E., 1965, p. 12-13 apud SHARPE, 2011, p. 42).
\end{abstract}

O mundo dos camponeses referenciado pelo historiador fala também pode ser divisado nas entrevistas das mulheres do N. R. Capão Seco, quando elas mencionam os hábitos e elementos culturais que deixaram de existir devido às mudanças trazidas pelo agronegócio, principalmente no que tange aos ideais comunitários. Enedina Antônia de Souza, de 76 anos, afirmava constantemente, em sua fala, que os tempos de sua juventude, quando ainda existiam práticas voltadas à agricultura de subsistência, eram muito melhores do que os de hoje. Quando indagada se existia mais união antigamente, ela respondeu: "Tinha. De primeiro o pessoal tinha mais união. Agora não tem não. Agora o povo é largado demais" "7. Esse espírito de comunidade, que ela diz não ser mais característico do povo dali, também existia com relação ao cerrado. Enedina reclama, ainda, da ausência de liberdade em relação à terra: antes da reforma agrária que beneficiou o agronegócio e criou núcleos rurais loteados, a ideia de propriedade era menos latente e o cerrado estava disponível para quem quisesse dele usufruir. Segundo sua fala, hoje em dia, se alguém entra na terra de outro, corre risco de vida.

[...] de primeiro o cerrado era de todo mundo. Se você chegasse e arranjasse, você apanhava. Se eu chegar e arranjar, apanhava. Não tinha esse negócio de falar, ué, aquele lote ali... tem aquele lote ali, por exemplo, eu não entro lá pra apanhar uma fruta, se eu não tiver eu não vou lá. Se isso aqui fosse um cerrado e tivesse, eu apanhava, porque todo mundo era dono do cerrado.

Depreende-se, dessa fala, que no passado vivido por Enedina, onde o cerrado ainda era abundante, existia mais união entre as famílias vizinhas, pois a vinda do agronegócio trouxe consigo a imposição da propriedade privada. A noção de 
cooperativismo também é evocada quando algumas entrevistadas lembram dos mutirões realizados nas fazendas com o objetivo de preparar a roça de determinado vizinho para o plantio. Esse tipo de atividade, que era muito comum na região, pode ser denominado de diversas maneiras: raposa, muxirão, mutirão ou treição. A pesquisadora Maria Cristina Campos Ribeiro (2016), ao analisar o Diário de Treição, da senhora Marlene Pereira, que fala dessa prática na cidade de Pirenópolis (GO), traz a seguinte descrição:

\begin{abstract}
No diário são elencados alguns espaços. O espaço da espera é o lugar onde os jovens se encontram para prosseguir para a festa, numa fazenda vizinha. Ao chegarem na localidade da treição festiva, primeiramente, se aglomeram na varanda onde cantam uma música saudando os donos da casa e solicitam acolhida e acesso à mesma de forma simbólica. Só depois de orar ou rezar o terço, como se fossem recebidos também no âmbito do sagrado, adentram o espaço da casa, até chegarem na varanda e nos fundos, ocupando, assim, os diversos ambientes da fazenda. Historicamente, a maneira como o mundo rural é percebido pelos camponeses revela a profunda ligação com a terra enquanto espaço próprio, onde a vida se constrói a duras penas e muitas vezes com lutas para protegê-la, bem como o direito de estar em casa. (RIBEIRO, 2016, p. 7).
\end{abstract}

O relato da senhora Enedina mostra-se rico a respeito dessa prática, pois apresenta detalhes sobre o trabalho que era realizado nas fazendas, destacando a diferença entre os tipos de mutirões. A treição, especificamente, é um tipo de organização em que o mutirão é precedido por uma surpresa, fator que explica o nome conferido à prática, uma variação da palavra "traição", justamente por se tratar de algo planejado às escondidas. O dono da fazenda que, segundo ela, sofrerá a traição, é surpreendido no meio da noite pela cantoria dos companheiros que, ao raiar do dia, iniciam os trabalhos na roça. A senhora Enedina ainda explica, junto à definição dos tipos de mutirão, um pouco sobre a divisão do trabalho entre homens e mulheres.

Tinha o muxirão das mulher fiar. Fiava o dia inteirinho, ali sentada fiando, quando - e os homem pra roça - quando era de tarde juntava tudo. Quando era traição, eu falava, vamos dar uma traição em fulano, aí eu chamo o povo, mas calado - era traição mesmo - aí quando é a noite junta aquela "homaiada", aquela "muiezada" tudo com as suas roda na cacunda e vai pra sua casa, lá eles canta na porta da sua casa, à noite, n/é... às base da meia noite ali, o povo canta na porta, n/é... e a traição dá em você, você num tá sabendo, aí você acorda assustada, aí quando é no outro dia cedo os homem vai pra roça, as mulher senta na... vai fiar. Por exemplo, eu levo o que comer, porque você não tá esperando, não arruma, n/é... as vezes a gente leva carne, leva um algodão arrumado, leva coisa, biscoito... tudo as mulher arruma. Os homem, os homem tá na roça, não tá nem sabendo se tem traição. Quando chega a "pionagem" lá, mas tá tudo arrumado, pro povo, n/é? Era bom demais. De primeiro era, agora não tem divertimento, até festa de agora não é que nem as festa de primeiro, n/é... tem prazer de o povo ir não. 
O fim da sua fala dá a entender que, naquela região, não se vê mais esse tipo de movimentação, o que certamente se deve à mudança de valor conferido à terra pelos que agora a possuem. Outra entrevistada que nos fala sobre essa movimentação tradicional é Sebastiana Antônia do Nascimento, de 87 anos. Ela conta que mora no N. R. Capão Seco há mais de 30 anos, mas antes disso vivera numa comunidade próxima, chamada São Bernardo, da qual foi desapropriada com a família. Nas suas palavras, "esses desapropriador que andava desapropriando todo mundo, desapropriou nós, n/é... de lá [...] aí nós viemos pra esse Capão Seco". Proveniente de família camponesa, ela e a família viviam da terra antes de serem expropriados, de modo que também ela menciona o hábito dos mutirões nas fazendas.

Antigamente o povo fazia serviço era assim: fazia uma roça, uma roça (trecho incompreensível) como o povo fala, n/é... aquele mundo velho de roça, aí juntava os peão moradores, colega, n/é... todo mundo e limpava aquela roça, plantava. Limpava eles mesmo, n/é? Agora, depois que entrou esse aí não precisou de ninguém fazer isso mais, não tinha lugar de fazer a roça, n/é... que eles plantava é no campo.

A fala de Sebastiana mostra a relação existente entre a economia de subsistência e o espírito comunitário entre os vizinhos, que partilhavam da mesma condição com a terra. Sendo os camponeses expropriados com a introdução do agronegócio, ocorreu uma quebra das relações anteriormente estabelecidas. As palavras de Enedina e Sebastiana acerca do espírito comunitário que envolvia as antigas relações sociais da região apontam para uma dimensão cultural advinda do contato entre o homem e a natureza que o circunda, neste caso, o cerrado. Essas fontes demonstram a relevância da história oral para se obter esse grau de sensibilidade, pois, como já mencionado, talvez as fontes escritas não pudessem atingir o mesmo resultado em termos de qualidade.

Podemos perceber, a partir da fala dessas mulheres, que houve mudanças nas interações entre os membros de sua sociedade por conta da quebra do vínculo anterior entre o homem e a natureza que o cercava. Mesmo assim, muitas delas ainda guardam saberes adquiridos no passado, como o uso de plantas com potencial curativo extraídas do cerrado. Tercina Neres de Santana, por exemplo, de 73 anos, também proveniente de família camponesa, é considerada pela comunidade uma conhecedora de plantas com poder curativo. Ela preserva em seu quintal vários exemplos de espécies nativas da região que podem ser usadas para curar doenças que vão de gripe a infecções. Quando perguntada se utilizava plantas do cerrado, afirmou não ter mais acesso a alguns tipos, 
que se tornaram raros após os desmatamentos, como "uma tal de 'poainha', que era muito bom pra menino quando estava nascendo dente, papaconha [...] Agora onde que minha neta mora acho que pode arranjar".

Fotografia 1: Plantas do quintal da senhora Tercina ${ }^{8}$.

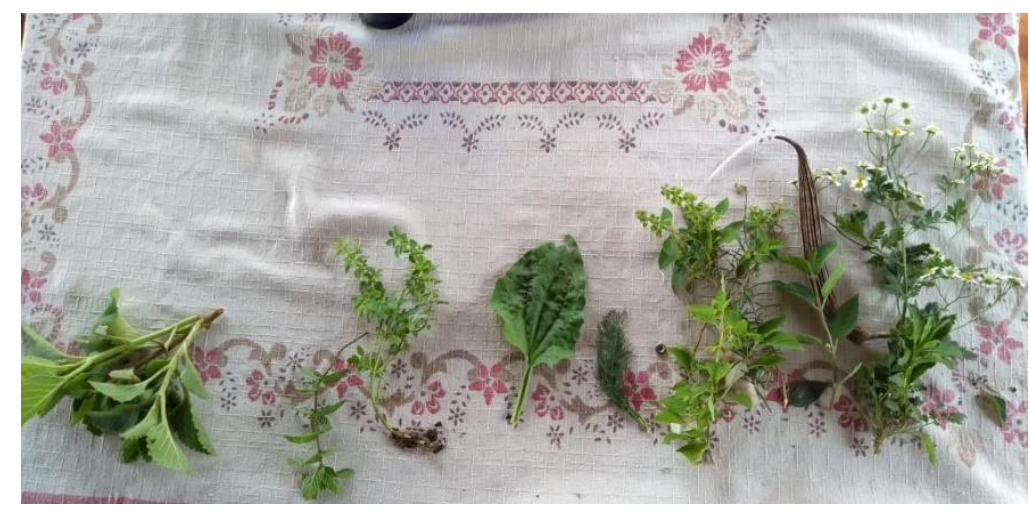

Fonte: Arquivo pessoal (2018)

Orgs.: Isabella Ferreira Viana Ribeiro e Lívia Gomes de Luccas (2018)

Tercina conta que muitos vizinhos a procuram para que recomende remédios. Ela mencionou o caso de uma menina que tinha febre, para quem fez um remédio derivado de uma combinação de plantas. "Outro dia tinha uma menina mesmo - nós morava aqui -, ela estava numa febre, chega não estava adornada, aí eu fiz, torrei o corro santo e a batata, e dei ela. Quando foi de tarde ela já estava boa". Ao que tudo indica, o conhecimento que ela possui sobre a utilização dessas plantas foi aprendido com a sua mãe, que, em suas palavras, "era muito 'remedeira". Ela afirma sentir falta do cerrado por não encontrar mais algumas plantas. "Ficou esquisito, n/é... porque muito remédio que tinha no cerrado, agora não tem mais, n/é?" E menciona algumas que não encontra mais onde mora, por exemplo "uma tal de douradinha do cerrado, ela dá uma folhinha assim, a folhinha dela é dura e dá uma florzinha assim desse tamanho, é uma beleza, um 'remedião',".

Assim como Tercina, a senhora Sebastiana conta que também aprendeu com a mãe a fazer remédios a partir da extração de plantas do cerrado. A primeira receita que ela revela é do chá feito de uma planta chamada camargo. Trata-se de um palmito amargo, semelhante à guariroba, que, além de servir de alimento, possui propriedades medicinais. Ela conta que come o camargo e usa a água em que a planta foi fervida como remédio. "Se uma pessoa tiver lombriga, n/é... é só beber ele que bota a lombriga tudo fora". 
Segundo ela, "remédio de pobre que a gente tinha era assim, agora hoje em dia que tem remédio da cidade, ninguém bebe, n/é [...] ninguém vai beber a água do camargo (risos)", o que mostra a importância dessas plantas em sua sociedade antes da introdução dos medicamentos químicos. Ela afirma deter essa sabedoria porque ajudava a mãe, que era "meio assim doutora”, a fazer garrafadas com raízes de plantas. A mãe não só conhecia remédios, como também fazia benzimentos 9 .

\begin{abstract}
Depois você nem arranja isso mais assim. Ela arrancava papaconha, vocês não sabem o que que é isso, mas eu vou falar, n/é (risos)? Era papaconha ela arrancava. Era velame ela arrancava, velame é bom pro pelo (referia-se ao cabelo) [...] Tinha um tal de para-tudo. Quando tá tossindo muito você faz um chá de para-tudo e sopra ele de um copo pro outro assim e tira aquela espuma [...] Tinha carapiá. Carapiá também é bom, pra remédio pra gripe [...] Naquele tempo que o povo, não existia médico, né, era raiz do mato.
\end{abstract}

Outra senhora que possuiu, desde cedo, uma relação de proximidade com o cerrado é Valdeci Alves de Sousa, de 84 anos. Ela chegou ao N. R. Capão Seco há mais de quarenta anos, após ser desapropriada das terras em que vivia com a família na região do Jardim II. “Eu cheguei aqui, eles me desapropriou lá e me deu esse lote aqui, e me pediu pressa modo eu vim logo, antes de outro entrar, que aqui nesse lugar não tinha morador nenhum, era só cerrado”. Ela conta o quanto sofreu ao chegar, pois, na época, tinha seis filhos e acabara de ficar viúva. Desde pequena, lidava com a terra e continuou trabalhando em fazendas de terceiros para sustentar os filhos, participando inclusive do processo de desmatamento do cerrado. "Eles arrancava com o trator e nós ia pra juntar as raiz, pra amontoar, pra poder por fogo [...] trabalhei demais em roça, ai quando eu fui aposentar, eu falei, 'olha desde a idade de 8 anos que eu trabalho só em roça'”. Dessa relação com a terra, ela passou a conhecer muitas plantas do cerrado, algumas das quais trouxe para seu quintal: “um tal de algodãozinho do campo, tinha um tal de creme, tinha papaconha, tinha sexto sangria. Era tanto remédio do cerrado que a gente arrancava pra beber". Ela também confirma a dificuldade de se acessar essas plantas hoje em dia. "Não tem mais porque desmataram tudo". Algumas sementes ela diz ter recolhido durante os desmatamentos e plantado em seu quintal.

No entanto, mesmo sentindo falta do cerrado, da beleza da vegetação e das plantas hoje não mais encontradas, Valdeci afirma achar o clima mais fresco agora, justamente por não ter mais que trabalhar no sol, como fez por muito tempo. "Eu sinto assim que ficou mais fresco pra mim, porque eu trabalhava muito no sol, na lavoura muito quente, 
n/é... aí eu estou sentindo mais fresco". Devemos analisar essa afirmação não apenas pelo viés da contradição que ela manifesta - uma vez que, na verdade, o clima do Centro-Oeste ficou mais quente com os desmatamentos -, mas perceber como aí se revela um aspecto da memória que pode ser induzido pelo presente daquele que produz a recordação. Segundo Pollak, (1992, p. 4) "as preocupações do momento constituem um elemento de estruturação da memória". A senhora Valdeci não sabe dizer se, no geral, a falta do cerrado deixou o clima mais quente, mas, levando em conta sua trajetória de trabalho árduo, por ficar agora em casa, acredita estar mais fresco.

Esse último elemento da memória - a sua organização em função das preocupações pessoais e políticas do momento - mostra que a memória é um fenômeno construído. Quando falo em construção, em nível individual, quero dizer que os modos de construção podem tanto ser conscientes como inconscientes. O que a memória individual grava, recalca, exclui, relembra, é evidentemente o resultado de um verdadeiro trabalho de organização (POLLAK, 1992, p. 4-5).

A entrevista de Valdeci enfatiza seu histórico sofrido de trabalho, na situação de viúva que trabalhou a vida toda para sustentar sozinha os seis filhos, inclusive durante o processo de derrubada das árvores do cerrado. Da mesma forma, cada relato das demais senhoras apresenta particularidades, o que mostra que a memória, apesar de se construir dentro de um contexto social, como já foi falado, pode apresentar diferentes pontos de vista sobre um mesmo assunto, conforme as vivências de cada pessoa.

Esse fator pode ser demonstrado pela entrevista com a senhora Nelsiana Gomes de Matos, de 57 anos. Ela viveu a vida toda no N. R. Capão Seco, passando todo o tempo ao lado da mãe, que faleceu poucos meses antes da entrevista. Por esse motivo, seus relatos vão sempre ao encontro da sabedoria deixada pela genitora. Ela conta sobre o passado camponês da família, que se sustentava pelo trabalho com a terra. Segundo ela, até mesmo as roupas eram feitas com o algodão plantado na roça e fiado pela mãe no tear.

\footnotetext{
Era minha mãe que fazia roupa pra eles vestir, porque não tinha como comprar, não tinha. Aí minha mãe pegava algodão na roça, fiava, fazia o fio, tecia no tear que ela ainda tem ali até hoje, as coisa que ela trabalhava, tem roda, tem tudo. Ela que fazia roupa pra gente vestir, porque naquela época não tinha. Ela fazia roupa pro meu pai, pros meus irmãos. Até as roupa de cama, tudo era ela que fazia, porque não tinha como comprar.
}

Sua mãe, mesmo sendo deficiente de uma das mãos, conservou o hábito de fiar até os últimos anos de vida, prática que se devia à sabedoria tradicional das famílias que subsistiam da terra, plantando algodão para tecer as próprias roupas. Nelsiana guarda com 
carinho alguns tecidos feitos pela mãe. A sabedoria de Dona Lica, que, quando viva, era considerada a moradora mais velha do N. R. Capão Seco, chegou a ser registrada pelo jornal Correio Brasiliense há alguns anos.

Fotografia 2: Reportagem do Correio Brasiliense com a mãe de Nelsiana

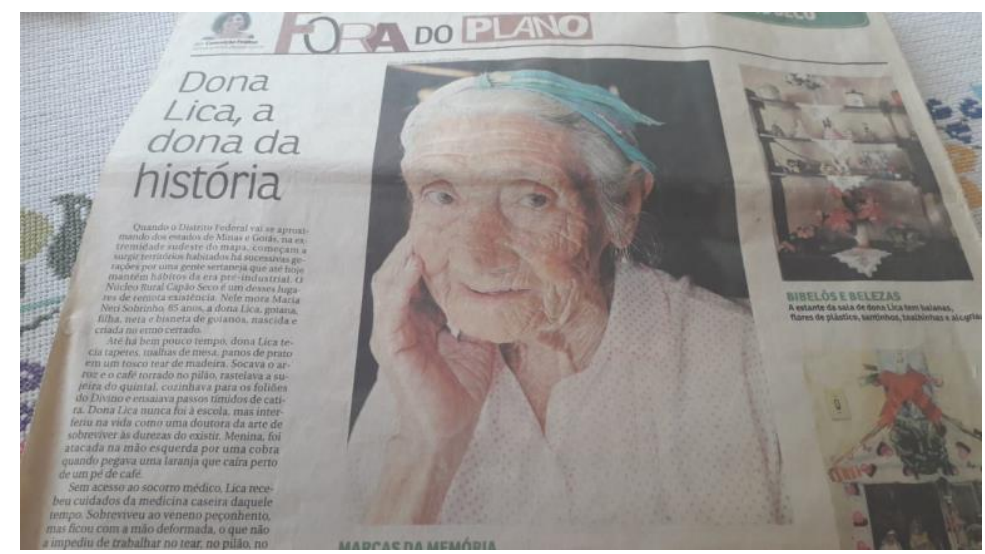

Fonte: Arquivo pessoal (2018)

Orgs.: Isabella Ferreira Viana Ribeiro e Lívia Gomes de Luccas (2018)

Ao falar sobre o apreço da mãe pela prática de fiar, a senhora Nelsiana reforça a noção do apego dos sujeitos do campo à tradição, atitude em que podemos verificar saudosismo com relação ao passado. Esse mesmo aspecto também aparece em outras entrevistas. A senhora Enedina, por exemplo, afirma preferir a maneira como a comunidade se organizava antigamente.

Eu preferia muito, se pudesse voltar aquele tempo... eu nasci e criei assim, n/é... pouco tempo depois que pegou, que loteou aqui e foi virando assim que acabou, as diversão boa acabou. Aqui só ainda tem a Festa do Divino, que ainda sai e as reza que nós ainda faz, mas outras coisa, não tem muita coisa aqui que a gente acha de trazer não. De primeiro, até esse campo (faz referência ao campo de futebol abandonado em frente à casa) aí ó, vocês tá vendo, não tá vendo o campo, como é que tá? De primeiro era movimentado esse campo. Quando dava no fim de semana, no sábado, no domingo, era torneio, era coisa, tudo, aí acabou... (grifo meu).

Sobre as festividades que movimentam a comunidade, percebe-se, ainda, a forte presença do catolicismo. Quando perguntadas sobre o assunto, as senhoras mencionaram a Folia do Divino Espírito Santo, festa tradicional no estado de Goiás, e a novena de São Sebastião. Segundo Nelsiana, que é católica, assim como as outras senhoras, "a festa que tem pra nós aqui religiosa é janeiro, a novena, de dia 11 até o dia 19. Todo ano a gente tem, aí tem a renda ficava pra igreja aí, agora vai pro PAD-DF”. Ela se refere à igreja localizada no PAD-DF, que passou a representar as comunidades em volta. 
Nas falas das entrevistadas Tercina e Valdeci, percebemos uma contradição com relação à vinda do agronegócio e à destruição do cerrado, pois ambas, apesar de concordarem que a vegetação nativa faz falta, disseram ser o novo sistema responsável por melhorias em sua comunidade, como a geração de empregos e a melhoria na infraestrutura. A opinião da senhora Sebastiana, por outro lado, vai se aproxima do que foi dito por Enedina, preferindo a vida que levavam antes. "Uai, o cerrado se era importante? Pra mim era. Pra mim era importante, que era bom demais ter o cerrado, n/é? Agora hoje em dia você vê esses 'pelame' aí, esses 'peladão'”. Ainda que leve em conta as melhorias na infraestrutura da comunidade, ela afirma que "antes era muito melhor do que é agora, porque tem postinho, porque tem asfalto. O povo não ligava pra isso porque todo mundo tinha, era aberto pra todo mundo, n/é... não era só pra alguns".

Apesar das controvérsias apontadas acima, as falas dessas mulheres mostram a riqueza de saberes que vem se perdendo com a devastação do cerrado, de forma a evidenciar a relevância da memória para promover o resgate desse conhecimento. Quando muitas delas admitem ter adquirido diversos conhecimentos com suas mães, vemos uma perpetuação de saberes a partir da oralidade, já que se trata de sociedades que foram alfabetizadas há pouco tempo. Das cinco mulheres entrevistadas, apenas uma, a mais nova dentre elas, frequentou a escola; as outras nem sequer assinavam seus nomes. Até mesmo seus descendentes, segundo os relatos, tiveram dificuldades de acesso à escola, muitos dos quais não chegaram a concluir o ensino básico.

Depreende-se, assim, que o uso da memória é algo fundamental para a construção da história dos camponeses, considerando que muitos deles, sobretudo os idosos, não chegaram a se alfabetizar. Nesse contexto, a ausência da escrita eleva a memória a uma categoria privilegiada. Usa-se muito mais esse artifício nas sociedades com pouco ou nenhum letramento. "Na maior parte das culturas sem escrita, e em numerosos setores da nossa, a acumulação de elementos na memória faz parte da vida cotidiana" (GOODY, 1977a, p. 35 apud LE GOFF, 2013, p. 391) ${ }^{10}$.

\section{Considerações finais}

A partir da memória das mulheres do N. R. Capão Seco, percebemos uma comunidade formada por um conjunto de fatores que vem se modificando nas últimas 
décadas. Muitas práticas de antigas famílias perderam-se após a devastação do cerrado em função da introdução do agronegócio, que estabeleceu uma nova dinâmica de trabalho com a terra, a qual excluiu em larga escala os antigos moradores do local. As relações sociais anteriores à introdução do agronegócio na região fazem agora parte de um outro tempo, e o que nos resta é a memória para tentar resgatar o que não foi lançado no esquecimento, mas que ainda faz parte da identidade camponesa desses sujeitos.

Pelos relatos das entrevistadas, percebemos que sua vida não foi fácil, não só pelo contexto de desapropriações aqui discutido ou pelo esvaziamento das tradições causado pela mudança no cenário local, mas também por terem passado parte da vida sozinhas. A viuvez precoce dessas mulheres aponta a necessidade da escolha de mulheres e não homens como porta-vozes da memória de sua sociedade. Da mesma forma, isso revela sua propensão a transmitir os ensinamentos adquiridos pela experiência aos seus descendentes. Talvez elas sejam a última via de conexão com o mundo camponês de seus antepassados.

Mesmo com as dificuldades enfrentadas ao longo da vida, essas mulheres conseguiram acumular saberes camponeses que precisam ser registrados, por isso é urgente a valorização da memória como ferramenta de produção historiográfica. Das entrevistas, percebemos o quanto o cerrado foi importante para a construção da identidade das famílias que vivem hoje no N. R. Capão Seco, estimulando o espírito comunitário entre a vizinhança, já que a vegetação era comum a todos e dentro dela estavam disponíveis uma diversidade de plantas e frutos que podiam ser utilizados como alimentos e remédios. Esse ambiente, considerado inóspito pelos desenvolvimentistas direcionados pelo sistema capitalista, possibilitou, todavia, o sustento de famílias por muitas gerações e o florescimento de elementos culturais camponeses que não foram esquecidos pelas mulheres do N. R. Capão Seco. 
${ }^{1}$ Não devemos confundir com o tipo de assentamento feito pelo INCRA. Trata-se aqui de um termo referenciado pelo próprio nome do PAD-DF (Programa de Assentamento Dirigido do Distrito Federal), que faz parte de um projeto do Estado, a partir da década de 1970, para modernizar a agricultura das áreas rurais de Brasília. De acordo com Rocha (1992, p. 78), “em 1977, foi criado o PAD/DF com 86 lotes, tendo cada um deles em média 300 ha, representando 22,75\% da terra arrendada no Distrito Federal". O PAD-DF é um exemplo da atuação do Estado na mediação da reconfiguração agrícola nesta região. Este último, atuou na desapropriação de parte das áreas disponíveis "e repassou estas terras aos agricultores que deveriam explorá-las sob um regime de arrendamento, tendo apenas a posse de fato, mas não de direito, do seu meio de produção" (ROCHA, 1992, pp. 81-82).

${ }^{2} \mathrm{O}$ inventário é um documento construído a partir de uma série de trabalhos, inclusive o levantamento de fontes que possibilitem conhecer a dinâmica das comunidades atendidas pela escola. No Distrito Federal, a instituição que pretende se adequar à categoria de "escola do campo" precisa reunir informações para a construção do referido documento. Envolvidos com este trabalho estavam os professores do CED PADDF, Isabella Ferreira Viana Ribeiro, Livia Gomes de Luccas e Vanilson José Lourenço.

${ }^{3}$ De acordo com Silva (2011, p. 1), o Patrimônio Cultural Imaterial trata dos elementos não concretos e intangíveis "ícones do não-dito, de representações, de costumes, de tradições e/ou de saberes, vide-se o artesanato, a fabricação de instrumentos, a cultura popular, as brincadeiras, as formas de expressão, as artes visuais, as festas religiosas, as celebrações rituais e os lugares de sociabilidade".

${ }^{4}$ A Fundação Zoobotânica do Distrito Federal ficou extinta de acordo com o Decreto 20.976, DE 27 DE JANEIRO DE 2000. “Art. $1^{\circ}$ Fica extinta a Fundação Zoobotânica do Distrito Federal, na forma da Lei $n^{\circ}$ 2.294, de 21 de janeiro de 1999, sendo suas competências e atribuições integradas à Secretaria de Agricultura do Distrito Federal”. Disponível em: http://www.tc.df.gov.br/sinj/Norma/37844/Decreto_20976_27_01_2000.html. Acesso em 05.01.2019.

${ }^{5}$ Polocentro (Programa Para o Desenvolvimento do Cerrado), criado em 1975. Proceder (Programa NipoBrasileiro Para Desenvolvimento do Cerrado), criado em 1976.

${ }^{6}$ De acordo com a estudiosa da Unicamp, Carolina Octaviano (2010), a Revolução Verde baseia-se em tecnologias agrícolas que visam aumentar de forma considerável a produção de alimentos, sobretudo em países menos desenvolvidos. Esse movimento surge com a promessa de acabar com a fome mundial, por conta do progressivo aumento da população. Porém, não foram considerados os impactos ambientais que essa nova forma de lidar com a terra poderia causar. No Brasil, a Revolução Verde foi introduzida durante a ditadura militar. Disponível em:http://comciencia.scielo.br/scielo.php?script=sci_arttext\&pid=S151976542010000600006\&lng=pt\&n rm=iso. Acesso em 08 de janeiro de 2019.

7 As transcrições das entrevistas foram realizadas com base nas indicações fornecidas pelo texto $A$ transcrição da fala do homem rural: fidelidade ou caricatura?, construído a partir do trabalho do grupo de pesquisa do programa de pós-graduação em sociologia da UNESP, liderado por Dulce C. A. Whitaker (1995).

${ }^{8}$ Da esquerda para a direita: dois tipos de hortelã (bom para a gripe), poejo (faz bem para crianças), tanchagem (cura inflamações), erva-doce, alfavaca, erva-cidreira, quiabo (quando torrado é bom para curar tosse), quitoco e artimijo (os dois últimos juntos são bons para febre).

${ }^{9}$ Prática de cura que relaciona plantas medicinais com a religiosidade popular.

${ }^{10}$ Essas sociedades são consideradas primitivas por não possuírem escrita e, portanto (segundo os moldes europeus), não possuírem história. No entanto, elas davam grande valor à memória como via para se chegar aos eventos passados. Algumas sociedades sem escrita tinham membros que eram especialistas em memória, também chamados de genealogistas, por conseguirem armazenar informações sobre a genealogia das principais famílias, e tradicionalistas, por contarem a história dos reis (LE GOFF, 2013, p. 393).

\section{REFERÊNCIAS}


AMADO, Janaina. O grande mentiroso: tradição, veracidade e imaginação em história oral. Revista História. São Paulo, Ed. UNESP, V 14, 1995. p. 125-136.

BARBOSA, Altair Sales. O cerrado acabou - entrevista com Altair Sales Barbosa. [Entrevista concedida ao Portal Raízes Jornalismo Cultural]. Portal Raízes Jornalismo Cultural, 2015. Disponível em: https://www.portalraizes.com/o-cerrado-acabouentrevista-com-altair-sales-barbosal. Acesso em: 14 de janeiro de 2019.

BRAGA, Maria Lúcia de S. As políticas desenvolvimentistas e ambientais brasileiras e seus impactos na região dos cerrados. In: BRAGA, Maria Lúcia de S.; DUARTE, Laura Maria G. (Org.). Tristes Cerrados: sociedade e biodiversidade. Brasília: Paralelo 15, 1998. 299 p. p. $95-123$.

BURKE, Peter. Abertura: a nova história, seu passado e seu futuro. In: Peter Burke (Org.). A escrita da história: novas perspectivas. Tradução de Magda Lopes. São Paulo: Editora Unesp, 2011. 363 p. p. 7-38.

CARNEIRO, Ana; CIOCCARI, Marta (orgs.). Retrato da Repressão Política no Campo - Brasil 1962-1985 - Camponeses torturados, mortos e desaparecidos. Brasília: MDA, 2010. 360 p.

COOPA-DF. Cooperativa do PAD-DF. AgroBrasília 2016 movimenta o agronegócio do Cerrado. 2016. Disponível em: https://coopadf.com.br/noticias/208-agrobrasilia2016-movimenta-o-agronegocio-do-cerrado. Acesso em: 07 de janeiro de 2019.

DUARTE, Élio Garcia. Manifestações camponesas em Goiás. Perspectivas para uma pesquisa. História cultural. Revista Goiânia, vol. 6 jan./jun., 2001. p. 113-134.

FERREIRA, Idelvone M.; MENDES, Estevane de P. P. Ocupação e povoamento dos territórios centrais do Brasil: política fundiária e trabalho do século XVIII ao XX. XXI Encontro Nacional de Geografia Agrária, Uberlândia/MG, 2012.

HALBWACHS, Maurice. A memória coletiva. Tradução de Beatriz Sidou. São Paulo: Centauro, 2003. 222 p.

HALL, Stuart. A identidade cultural na pós-modernidade. Tradução de Tomaz Tadeu da Silva e Guacira Lopes Louro. Rio de Janeiro: DP\&A, 2006. 102 p.

LE GOFF, Jacques. História e Memória. Tradução de Bernardo Leitão... [et al]. $7^{\mathrm{a}}$ ed. revista. Campinas, SP: Editora da Unicamp, 2013. 499 p.

LYRIO. Emmanuel F. M. Considerações em torno da administração direta e indireta do Distrito Federal. R. Serv. Público: Brasília, 1973. p. 113-140.

MAGALHÃES, Luiz Ricardo. Brasília, a utopia do centro. Dissertação de mestrado, Universidade Federal de Goiás (Faculdade de Ciências Humanas e Filosofia): Goiânia, 2004. 
MATOS, Júlia S.; SENNA, Adriana K. de. História oral como fonte: problemas e métodos. Historiae, Periódicos FURG: Rio Grande/RS, 2011. p. 95-108.

MATOS, Patrícia Francisca; PESSÔA, Vera Lúcia Sa. A modernização da agricultura no brasil e os novos usos do território. Geo UERJ - Ano 13, nº 22, v. 2, $2^{\circ}$ semestre de 2011. p. 290-322.

MEDEIROS, Silvana A. F. de. Agricultura moderna e demandas ambientais: o caso da sustentabilidade da soja nos cerrados. In: BRAGA, Maria Lúcia de S.; DUARTE, Laura Maria G. (Org.). Tristes Cerrados: sociedade e biodiversidade. Brasília: Paralelo 15, 1998. 299 p. p. 127-145.

OCTAVIANO, Carolina. Muito além da tecnologia: os impactos da Revolução Verde. ComCiência nº.120. São Paulo, 2010. Disponível em:

http://comciencia.scielo.br/scielo.php?script=sci_arttext\&pid=S1519765420100006000 06\&lng=en\&nrm=iso. Acesso em: 08 de janeiro de 2019.

POLLAK, Michael. Memória e identidade social. Estudos históricos, Rio de Janeiro, vol. 5 , n. 10, 1992. p. 200-212.

RIBEIRO, Maria Cristina C. Mãos que oram, celebram e trabalham. Anais do II Simpósio Internacional de História das Religiões da ABHR e XV Simpósio Nacional de História das Religiões da ABHR, Florianópolis-SC, 2016.

RICOEUR, Paul. A memória, a história, o esquecimento. Tradução de Alain François [et al.]. Campinas, SP: Editora da Unicamp, 2007. 535 p.

ROCHA, Luiz Augusto. Modernização e diferenciação social (o caso do Programa de Assentamento Dirigido do Distrito Federal - PAD/DF). Dissertação de Mestrado, Universidade Federal do Rio Grande do Sul (Programa de Pós-graduação em Sociologia): Porto Alegre, 1992.

SANTOS, André S. Aspectos da ocupação e desenvolvimento do centro-oeste brasileiro: apontamentos sobre a relação entre a agropecuária e a sustentabilidade do meio natural na região de Barra do Garças/MT. Anais do Congresso Internacional de História da UFG, Jataí-GO, 2016.

SEDUH/DF. Secretaria de Estado de Desenvolvimento Urbano e Habitação. Dossiê Rural. Lei 4.504/64 (Estatuto da Terra). Disponível em: http://www.seduh.df.gov.br/wp-conteudo/uploads/2017/09/lei_4504_30111964-1.pdf. Acesso em 17 de agosto de 2019.

SHARPE, Jim. A história vista de baixo. In: Peter Burke (Org.). A escrita da história: novas perspectivas. Tradução de Magda Lopes. São Paulo: Editora Unesp, 2011. 363 p. p. 39-63.

SILVA, Hélio de A. Problemas Fundiários do Distrito Federal. Mundo Jurídico, São Paulo, 2006. Disponível em: 
http://www.mundojuridico.adv.br/sis_artigos/artigos.asp?codigo=856. Acesso em: 08 de janeiro de 2019.

SILVA, Paulo Sérgio da. Patrimônio cultural imaterial: conceito e instrumentos legais de tutela na atual ordem jurídica brasileira. Anais do XXVI Simpósio Nacional de História - ANPUH, São Paulo, julho de 2011.

WITAKER. Dulce C. et al. A transcrição da fala do homem do campo: fidelidade ou caricatura? Cadernos de Campo: Revista de ciências sociais, Periódicos Unesp, São Paulo, v. 2, 1995, p 65-70.

Recebido em 28/04/2019.

Aceito para publicação em 07/06/2019. 